\title{
HUBUNGAN DUKUNGAN KELUARGA DENGAN PENURUNAN KECEMASAN PADA LANJUT USIA SAAT HOSPITALISASI
}

\author{
Rokhmatul Hikhmat ${ }^{*}$ Armelinda*
}

\begin{abstract}
ABSTRAK
Kecemasan merupakan salah satunya gangguan mental yang sering dialami lanjut usia saat menjalani hospitalisasi. Berdasarkan hasil studi pendahuluan yang dilakukan di Ruang Pratama dan Pratiwi Rumah Sakit Ciremai Cirebon selama 3 bulan terakhir didapatkan data jumlah pasien lansia sebanyak 246 pasien, yaitu 82 pasien pada bulan Desember, 83 pasien pada bulan Januari dan 81 pasien pada bulan Februari 2016. Dengan rata-rata usia 45-66 tahun. Tujuan penelitian ini adalah untuk mengetahui hubungan dukungan keluarga dengan penurunan kecemasan pada lanjut usia saat hospitalisasi di Ruang Pratama dan Pratiwi Rumah Sakit Ciremai Cirebon Tahun 2016. Penelitian ini bersifat deskriptif korelasi. Metode yang digunakan untuk penelitian ini adalah metode survei. Pengambilan data dilakukan dengan pendekatan cross sectional dengan menggunakan kuesioner. Teknik pengambilan sampel yang digunakan adalah purposive sampling, dengan jumlah sampel 45 responden.

Berdasarkan hasil uji stastistik Chi Square didapatkan Asymp.sig (p value) sebesar $0.005(0.005 \leq 0.005)$ maka Ho ditolak. Artinya ada hubungan yang signifikan antara dukungan keluarga dengan penurunan kecemasan pada lanjut usia saat hospitalisasi di Ruang Pratama dan Pratiwi Rumah Sakit Ciremai Tahun 2016.

Penelitian ini diharapkan dapat disempurnakan oleh peneliti selanjutnya, karena penelitian masih banyak membutuhkan perbaikan dan masukan. Serta dapat dijadikan sebagai bahan referensi dan masukan untuk penelitian lebih lanjut.
\end{abstract}

Kata Kunci : Dukungan Keluarga, Kecemasan, Lansia, Hospitalisasi

\begin{abstract}
Anxiety represent one of them mental disorder which is often experienced of elderly hospitalization. Pursuant to result of done antecedent study in Pratama room and Pratiwi room of Ciremai Hospital of Cirebon during last 3 months in getting data of is amount of patient of elderly counted 246 patient, that is 82 patient in December, 83 patient in January and 81 patient in Februari 2016. With age mean 45-66 year. Target of this research is to know family support relation with degradation of dread at continuing moment age of hospitalization in Pratama room and of Pratiwi room of Ciremai Hospital in 2016. This research have the character of descriptively of correlation. Method which in using for this research is survey method. Intake of data in doing with approach of sectional cross by using quesioner. Technique intake of sampel which in using is sampling purposive, with amount of sampel 45 responder. Pursuant to result of test of ststistik Chi Square got[by asymp.Sig ( value p) equal to 0.005 ( $0.005 \leq 0.005)$ hence Ho refused and Is Ha accepted. Its meaning there is relation which is signifikan between family support with degradation of dread at continuing moment age of hospitalization in Pratama room and Pratiwi room of Ciremai Hospital In 2016. This research is expected can be completed by its researcher, because research still requiring many input and repair. And also can be made upon which input and reference for furthermore research.
\end{abstract}

Key words : family support, anxiety, elderly, hospitalization 
** Alumni PSIK STIKes Cirebon Tahun 2016

\section{PENDAHULUAN}

Lanjut usia yaitu seseorang yang berusia 60 tahun atau lebih, lanjut usia resiko tinggi yaitu seseorang yang berusia 70 tahun atau lebih. Organisasi kesehatan dunia (WHO) menggolongkan lansia menjadi 4 yaitu: usia pertengahan (middle age) 45-59 tahun, lanjut usia (elderly) 60-74 tahun, lanjut usia tua (old) 75-90 tahun, usia sangat tua (very old) di atas 90 tahun. $^{1}$

Penduduk lanjut usia merupakan bagian dari anggota keluarga dan anggota masyarakat yang semakin bertambah jumlahnya sejalan dengan peningkatan usia harapan hidup. ${ }^{2}$ Pada tahun 2014 penduduk usia 60-75 tahun di Jawa Barat berjumlah 3.434.909 jiwa dengan jumlah penduduk laki-laki usia 60-75 tahun 1.650 .123 jiwa dan jumlah penduduk wanita usia 60-75 tahun 1.784 .786 jiwa. $^{3}$

Secara alamiah lanjut usia itu mengalami penurunan baik dari segi fisik, biologi, maupun mentalnya dan hal ini tidak terlepas dari masalah ekonomi, sosial, dan budaya sehingga perlu adanya peran serta keluarga dan adanya peran sosial dalam penanganannya. Menurunnya fungsi berbagai organ lansia menjadi rentan terhadap penyakit yang bersifat akut atau kronis. Ada kecenderungan terjadi penyakit degeneratif, penyakit metabolik, gangguan psikososial, dan penyakit infeksi meningkat. ${ }^{4}$

Menurut Stuart and Sundeen (1998) kecemasan adalah suatu keadaan perasaan kepribadian, rasa gelisah, ketidaktentuan, atau takut dari kenyataan atau persepsi ancaman sumber aktual yang tidak diketahui atau dikenal. Faktor yang mempengaruhi kecemasan antara lain frustasi, konflik, ancaman, harga diri, lingkungan yang berupa dukungan sosial, lingkungan, pendidikan, usia dan jenis kelamin. ${ }^{5}$

Prevalensi kecemasan pada dewasa dan lanjut usia di dunia pada sektor komunitas berkisar antara 15 sampai dengan 52,3\%. Di Indonesia gangguan kecemasan yang terjadi pada usia 55-64 tahun sebanyak 8\%, usia 65-74 tahun sebanyak 10\% dan pada usia lebih dari 75 tahun sebanyak 13\% dari jumlah penduduk seluruh Indonesia pada tahun 2013. ${ }^{6}$

Hasil wawancara dengan beberapa lansia mengatakan bahwa mereka sebenarnya lebih senang dirawat dan diurus oleh anggota keluarga, tapi karena tidak ingin merepotkan dan membebani anggota keluarga mereka akhirnya bersedia dirawat di rumah sakit. Walaupun setiap harinya mereka dirawat oleh seorang perawat tetapi mereka lebih senang jika anggota keluarganya juga ikut merawat mereka selama menjalani hospitalisasi. Sehingga membuat mereka tidak cemas dan merasa terbebani saat hospitalisasi.

Berdasarkan hasil studi pendahuluan yang dilakukan di Ruang Pratama dan Pratiwi Rumah Sakit Ciremai Kota Cirebon selama 3 bulan terakhir didapatkan data jumlah pasien lansia sebanyak 246 pasien, yaitu 82 pasien pada bulan Desember, 83 pasien pada bulan Januari dan 81 pasien pada bulan Februari 2016. Dengan rata-rata usia 45-66 tahun.

\section{METODE PENELITIAN}

Desain penelitian yang digunakan dalam penelitian ini adalah desain penelitian deskriptif korelasional. ${ }^{7}$ Pada penelitian ini, peneliti akan menjelaskan tentang dukungan keluarga yang dapat menyebabkan penurunan kecemasan pada lansia saat hospitalisasi.

Metode yang digunakan dalam mengumpulkan data survei penelitian ini adalah dengan menggunakan tanya jawab dengan penyebaran kuesioner melalui angket selama 15 menit. Setelah itu dilakukan perhitungan skor kuesioner. Dan hasil perhitungan ini akan dinilai menggunakan kriteria dan skala yang sudah ditentukan.

Pengambilan data dilakukan dengan cara cross sectional. ${ }^{7}$ Populasi dalam penelitian ini adalah seluruh pasien lanjut usia di Ruang Pratama dan Pratiwi Rumah Sakit Ciremai. Teknik pengambilan sampel pada penelitian ini menggunakan purposive sampling dengan jumlah sampel 44 responden dengan kriteria inklusi: 
1. Pasien lansia yang di rawat di Ruang Pratama/Pratiwi Rumah Sakit Ciremai

2. Pasien lansia yang dapat berkomunikasi dengan baik.

3. Pasien lansia yang baru masuk di ruang perawatan dan menjalani perawatan $1-4$ hari.

4. Pasien lanjut usia yang berusia 55-90 tahun.

5. Pasien dan keluarga bersedia ikut dalam penelitian.

Instrumen penelitian data terdiri dari kuesioner untuk mengukur dukungan keluarga dan kecemasan lansia

Analisis data dalam penelitian ini memakai sistem komputerisasi dengan menggunakan perangkat lunak statistik yang meliputi analisis univariat dan bivariat. ${ }^{9}$ Analisis univariat dilakukan dengan melakukan perhitungan persentase untuk mendapatkan gambaran distribusi responden serta untuk mendeskripsikan variabel bebas dan terikat. Analisis bivariat digunakan untuk menganalisis hubungan antara variabel bebas dukungan keluarga dan variabel terikat kecemasan lansia saat hospitalisasi. Uji statistik yang digunakan adalah uji chi-square. Interpretasi hasil perhitungan chi-square sesuai dengan kriteria adalah sebagai berikut: Jika nilai $\mathrm{p}<\mathrm{a}(=0,05)$ maka $\mathrm{H}_{\mathrm{a}}$ diterima, berarti ada hubungan dukungan keluarga dengan penurunan kecemasan pada lanjut usia saat hospitalisasi. Jika nilai $\mathrm{p}>\mathrm{a}(=0,05)$ maka $\mathrm{H}_{0}$ ditolak, berarti tidak ada hubungan dukungan keluarga dengan penurunan kecemasan pada lansia saat hospitalisasi.

\section{HASIL PENELITIAN}

\section{Dukungan Keluarga Pasien Lansia}

Tabel 1. Frekuensi Dukungan Keluarga Pasien Lansia

\begin{tabular}{|c|c|c|}
\hline Variabel & Frekuensi & Persentase $(\%)$ \\
\hline Baik & 23 & 51.1 \\
\hline Cukup & 21 & 46.7 \\
\hline Kurang & 1 & 2.2 \\
\hline Total & 45 & 100 \\
\hline
\end{tabular}

Berdasarkan tabel 1 Dukungan Keluarga Pasien Lansia didapatkan bahwa dukungan keluarga kategori baik sebanyak 23 orang $(51,1 \%)$, kategori cukup 21 orang $(46,7 \%)$ dan kategori kurang hanya 1 orang $(2,2 \%)$.

\section{Kecemasan Lanjut Usia Saat Hospitalisasi}

Tabel 2. Frekuensi kecemasan lanjut usia saat hospitalisasi

\begin{tabular}{ccc}
\hline Variabel & Frekuensi & Persentase $(\%)$ \\
\hline Tidak ada kecemasan & 22 & 48.8 \\
Kecemasan Ringan & 16 & 35.6 \\
Kecemasan sedang & 7 & 15.6 \\
\hline Total & 45 & 100
\end{tabular}

Berdasarkan tabel 2 kecemasan lanjut usia saat hospitalisasi didapatkan 22 orang $(48,8 \%)$ tidak merasa cemas, 16 orang $(35.6 \%)$ cemas ringan, dan 7 orang $(15,6 \%)$ cemas sedang. Masih terdapat 7 orang responden yang merasa cemas sedang disebabkan karena penyakitnya dan kurangnya dukungan keluarga. 


\section{Hubungan Dukungan Keluarga Dengan Penurunan Kecemasan Lanjut Usia}

Tabel 3. Hubungan dukungan keluarga dengan penurunan kecemasan lanjut usia

\begin{tabular}{lcccc}
\hline \multirow{2}{*}{ Dukungan Keluarga } & \multicolumn{3}{c}{ Kecemasan } & \multirow{2}{*}{ Total } \\
\cline { 2 - 5 } & Tidak cemas & Cemas Ringan & Cemas sedang \\
\hline Baik & 16 & 7 & 0 & 23 \\
Cukup & 6 & 9 & 6 & 21 \\
Kurang & 0 & 0 & 1 & 1 \\
\hline Total & 22 & 16 & 7 & 45 \\
\hline
\end{tabular}

Dari tabel diatas didapat $p$ value sebesar $0.004(0.004 \leq 0.005)$ maka Ho ditolak dan Ha diterima. Artinya ada hubungan yang signifikan antara dukungan keluarga dengan penurunan kecemasan lanjut usia.

\section{PEMBAHASAN}

\section{Dukungan Keluarga Pasien Lansia}

Dukungan Keluarga Pasien Lansia didapatkan bahwa dukungan keluarga kategori baik sebanyak 23 orang (52,3\%), kategori cukup 20 orang $(45,5 \%)$ dan kategori kurang hanya 1 orang $(2,3 \%)$.

Penurunan fungsi orang pada lanjut usia dapat menyebabkan berbagai macam penyakit yang berakibat buruk bagi kesehatan, karena hal itulah yang mendorong keluarga memberi dukungan lebih kepada pasien lanjut usia. Dukungan keluarga yang diberikan pada pasien lanjut usia untuk meningkatkan status kesehatannya dan untuk mencegah terjadinya komplikasi lebih lanjut.

Dukungan keluarga merupakan suatu strategi intervensi preventif yang paling baik dalam membantu anggota keluarga mengakses dukungan sosial yang belum digali untuk suatu strategi bantuan yang bertujuan untuk meningkatkan dukungan keluarga yang adekuat. Dukungan keluarga mengacu pada dukungan yang dipandang oleh anggota keluarga sebagai suatu yang dapat diakses untuk keluarga misalnya dukungan bisa atau tidak digunakan, tapi anggota keluarga memandang bahwa orang yang bersifat mendukung selalu siap memberikan pertolongan dan bantuan jika diperlukan. ${ }^{10}$

Dukungan keluarga telah mengkonseptualisasi dukungan sebagai koping keluarga baik dukungan keluarga yang eksternal maupun internal. Dukungan dari keluarga bertujuan untuk membagi beban juga member dukungan informasional. ${ }^{10}$

\section{Kecemasan pada Lanjut Usia Saat Hospitalisasi di Ruang Pratama dan Pratiwi Rumah Sakit Ciremai Kota Cirebon}

Kecemasan pada lanjut usia saat hospitalisasi di Ruang Pratama dan Pratiwi Rumah Sakit Ciremai Kota Cirebon didapatkan 22 orang $(48,8 \%)$ tidak merasa cemas, 16 orang (35.6\%) cemas ringan, dan 7 orang $(15,6 \%)$ cemas sedang. Masih terdapat 7 orang responden yang merasa cemas sedang disebabkan karena penyakitnya dan kurangnya dukungan keluarga.

Kecemasan adalah suatu perasaan takut yang tidak menyenangkan dan tidak dapat dibenarkan yang disertai gejala fisiologis, sedangkan pada gangguan sias terkandung unsur penderitaan yang bermakna dan gangguan fungsi yang disebabkan oleh kecemasan tersebut. ${ }^{11}$

Lanjut usia merupakan proses ilmiah dan berkesinambungan yang mengalami perubahan anatomi, fosiologis, dan biokimia pada jaringan atau organ yang pada akhirnya mempengaruhi keadaan fungsi dan kemampuan badan secara keseluruhan. ${ }^{12}$ 
Hospitalisasi merupakan pengalaman yang mengancam bagi setiap orang. Penyakit yang diderita akan menyebabkan perubahan perilaku normal sehingga klien perlu menjalani perawatan (hospitalisasi). Secara umum, hospitalisasi menimbulkan dampak pada empat aspek, yaitu privasi, gaya hidup, otonomi diri, dan peran. ${ }^{4}$

Suasana hati pasien lanjut usia akan berubah saat menjalani hospitalisasi. Keseharian pasien lanjut usia yang biasanya dihiasi dengan keceriaan, kegembiraan, dan senda gurau tiba-tiba diliputi kesedihan. Suasana keluarga pun menjadi sepi karena perhatian keluarga terpusat pada penanganan anggota keluarganya yang dirawat. Sebagian besar pasien lanjut usia yang dirawat merasa kesepian dan ketakutan akan ditinggalkan sendiri di rumah sakit atau ketakutan akan merepotkan semua anggota keluarga serta lamanya proses kesembuhan penyakitnya.

\section{Hubungan Dukungan Keluarga Dengan Penurunan Kecemasan pada Lanjut Usia Saat Hospitalisasi di Ruang Pratama dan Pratiwi Rumah Sakit Ciremai Kota Cirebon}

Dari hasil analisis didapat $p$ value sebesar $0.005(0.005 \leq 0.005)$ maka Ho ditolak dan Ha diterima. Artinya ada hubungan yang signifikan antara dukungan keluarga dengan penurunan kecemasan pada lanjut usia

Jenis dukungan keluarga yang dapat diberikan kepada pasien terdiri dari empat jenis atau dimensi dukungan antara lain : dukungan emosional, dukungan penghargaan (penilaian), dukungan instrumental, dukungan informative. ${ }^{13}$

Dukungan keluarga juga merupakan perasaan individu yang mendapat perhatian, disenangi, dihargai dan termasuk bagian dari masyarakat. ${ }^{13}$

Kecemasan adalah suatu perasaan takut yang tidak menyenangkan dan tidak dapat dibenarkan yang disertai gejala fisiologis, sedangkan pada gangguan ansietas terkandung unsur penderitaan yang bermakna dan gangguan fungsi yang disebabkan oleh kecemasan tersebut. ${ }^{11}$

Hospitalisasi merupakan keadaan dimana orang sakit berada pada lingkungan rumah sakit untuk mendapatkan pertolongan dalam perawatan atau pengobatan sehingga dapat mengatasi atau meringankan penyakitnya. Tetapi pada umumnya hospitalisasi dapat menimbulkan ketegangan dan ketakutan serta dapat menimbulkan gangguan emosi atau tingkah laku yang mempengaruhi kesembuhan dan perjalanan penyakit selama dirawat di rumah sakit. ${ }^{4}$

Hasil penelitian ini selaras dengan penelitian yang dilakukan Taufik Nugroho pada tahun 2014 mengenai dukungan keluarga, bahwa responden yang mendapatkan dukungan baik sebanyak 63,6\% dan dukungan kurang baik 36,4\%.

Hasil penelitian menunjukkan bahwa dukungan keluarga dapat mengurangi kecemasan pasien lanjut usia. Hal ini disebabkan adanya dukungan keluarga yang baik saat pasien lanjut usia menjalani hospitalisasi menjadi termotivasi untuk menjalani pola hidup yang lebih baik dan sehat. Dalam penelitian ini, pasien lanjut usia yang menjalani hospitalisasi merasakan bahwa keluarga telah mampu mewujudkan dukungan keluarga baik secara dukungan emosional dukungan penghargaan (penilaian) dukungan instrumental dan dukungan informatif.

\section{SIMPULAN}

1. Dukungan Keluarga Pasien Lansia termasuk kategori baik sebanyak 23 orang $(51,1 \%)$.

2. Kecemasan pada lanjut usia saat hospitalisasi didapatkan 22 orang $(48,9 \%)$ tidak merasa cemas.

3. Ada hubungan yang signifikan antara dukungan keluarga dengan penurunan kecemasan pada lanjut usia saat hospitalisasi ( $p$ value 0,005$)$ 


\section{SARAN}

1. Bagi Peneliti Selanjutnya

Penelitian ini diharapkan dapat disempurnakan oleh peneliti selanjutnya.

2. Bagi Keluarga Responden

Pasien diharapkan agar lebih mendukung keluarganya dalam keadaan apapun tertutama pada keluarga yang didalamnya terdapat lanjut usia dan sedang menjalani hospitalisasi.

3. Bagi Responden (Pasien Lansia)

Pasien diharapkan mampu mengutarakan apa yang diinginkan di butuhkan agar anggota keluarga lainnya lebih memahami dan mengerti dengan apa yang dibutuhkan dan diinginkan.

4. Bagi Rumah Sakit

Rumah sakit diharapkan dapat menerapkan pemberian dukungan keluarga pada asuhan keperawatan terutama pada pasien lanjut usia.

5. Bagi Institusi Pendidikan

Hasil penelitian ini diharapkan dapat dijadikan sebagai bahan referensi dan informasi bagi institusi.

\section{DAFTAR PUSTAKA}

1. Nugroho, W. Keperawatan Gerontik \& Geriatric. Edisi 3. Jakarta: EGC; 2000.

2. Widiyaningsih, Nuri. Factor-Faktor yang Berhubungan Dengan Kecemasan pada Lanjut Usia di Panti Wredha Dharma Bakti Kota Surabaya 2010. [Diakses tanggal 19 Januari 2016]. Diunduh dari http://eprints.ums.ac.id/

3. Badan Pusat Statistik Provinsi Jawa Barat. Jawa Barat Dalam Angka. Badan Pusat Statistik Provinsi Jawa Barat 2014. [Diakses tanggal 4 Februari 2016]. Diunduh dari http://jabar.bps.go.id

4. Asmadi. Konsep Dasar Keperawatan. Jakarta: EGC; 2015.

5. Stuart, G.W dan Sundeen, S.J. Buku Keperawatan Jiwa. Edisi 3. Jakarta: EGC;1998.

6. Departemen Kesehatan Republik Indonesia. Prevalensi Gangguan Emosional dan Kecemasan. [Diakses tanggal 5 April 2016]. Diunduh dari http://depkes.go.id/

7. Hidayat, Alimul. Metode Penelitian Keperawatan dan Teknik Analisis Data. Jakarta: Salemba Medika; 2012.

8. Hidayat, Alimul, A. A. Riset Keperawatan dan Teknik Penulisan Ilmiah. Jakarta: Salemba Medika;. 2012.

9. Notoatmodjo, S. Metodologi Penelitian Kesehatan. Jakarta: PT Rineka Cipta; 2010.

10. Friedman. Keperawatan Keluarga: Teori dan Praktik. Jakarta: Salemba Medika; 2003.

11. Direja, S. H. A. Asuhan Keperawatan Jiwa. Yogyakarta: Nuha Medika; 2011.

12. Fatmah. Gizi Usia Lanjut. Jakarta: Erlangga; 2010.

13. Effendi, S. Keperawatan Kesehatan Komunitas: Teori dan Praktek Dalam Keperawatan. Jakarta: Salemba Medika; 2008. 